\title{
Role of different kinds of dialysis in the treatment of refractory heart failure
}

\author{
Consolación Rosado, Rosario Manzanedo, Carmen Felipe, Begoña Alaguero, \\ Amelia Fildago, Carlos Chacón, Jesús Martín
}

Service of Nephrology of the Care Complex of Ávila, Ávila, Spain

Email: crosadorubio@hotmail.com

Received 27 November 2013; revised 29 December 2013; accepted 9 January 2014

Copyright (C) 2014 Consolación Rosado et al. This is an open access article distributed under the Creative Commons Attribution License, which permits unrestricted use, distribution, and reproduction in any medium, provided the original work is properly cited. In accordance of the Creative Commons Attribution License all Copyrights @ 2014 are reserved for SCIRP and the owner of the intellectual property Consolación Rosado et al. All Copyright (C) 2014 are guarded by law and by SCIRP as a guardian.

\section{ABSTRACT}

Cardiorenal syndrome is a severe and potentially lethal disease in which heart and kidney failures coexist. The classic treatment with loop diuretics is ineffective due to the resistance of the kidney to those drugs, which requires the use of other therapies, such as extracorporeal ultrafiltration and peritoneal dialysis. This last technique is useful both in the acute treatment of acute heart decompensation and the chronic management of heart failure, because it improves heart function by reducing the volume overload, which in turn contributes to improving the kidney function with a limited number of side effects, which makes it the technique of choice for the treatment of diuretic-resistant heart failure. In this review, we present a description of the different kinds of cardiorenal syndrome, as well as the different treatments that are used, with special attention to the different modalities of peritoneal dialysis.

\section{KEYWORDS}

Cardiorenal Syndrome; Peritoneal Dialysis;

Extracorporeal Ultrafiltration

\section{EPIDEMIOLOGY}

Heart failure is a common disease all over the world. It affects 5 million people in the United States [1], where more than 550,000 new cases are diagnosed each year, and it is the main cause of hospitalization in adults over 65 years old, so that $93 \%$ of the admitted patients present water retention, $42 \%$ are discharged without weight loss and $25 \%$ of the patients who are re-admitted develop resistance to diuretics [2].
Patients who suffer from heart failure present an increased incidence of chronic kidney failure: $30 \%$ to $50 \%$ suffer from chronic kidney disease with K/DOQI stages 3 to 5 , which are associated with a higher hospitalization rate and higher mortality [3]. Mortality increases annually in patients with heart failure by $15 \%$ for each creatinine increase of $0.5 \mathrm{mg} / \mathrm{dl}$, and by $7 \%$ for each decrease in the glomerular filtration rate of $10 \mathrm{ml} / \mathrm{min}$.

In hospitalized patients, there is a worsening in the renal function due to the decompensation caused by the heart failure. Therefore, when the patient reaches stage NYHA class IV and heart failure becomes refractory to the treatment, the six-month mortality rate increases to $50 \%[1]$.

\section{DEFINITION OF CARDIORENAL SYNDROME}

The kidneys and the heart work together to regulate the volume of extracellular fluid, natriuresis, cardiac output, arterial pressure, and glomerular filtration rate.

This relation also becomes clear in the pathologic states, where the dysfunction of both organs coexists. The term "cardiorenal syndrome" has recently been coined [4], and it is defined as the set of clinical situations characterized by the existence of a heart condition that leads to organic renal damage or to renal dysfunction, or as the existence of a kidney condition that leads to organic heart damage or cardiac dysfunction. Therefore, these two organs affect each other and the damaging effects are promoted and receive mutual feedback, so that the progression of the damage in the kidneys and the myocardium quickens.

There are five types of cardiorenal syndrome, but the same patient can evolve from one type to another $[3,4]$, as we describe in Table 1. 
Table 1. Different types of cardiorenal syndrome.

\begin{tabular}{|c|c|c|}
\hline CARDIORENAL SYNDROME & NAME & DESCRIPTION \\
\hline TYPE 1 & $\begin{array}{l}\text { Acute cardiorenal } \\
\text { syndrome }\end{array}$ & $\begin{array}{l}\text { It appears after an abrupt worsening of cardiac function, mainly due to the acute } \\
\text { decompensation of the chronic heart failure. }\end{array}$ \\
\hline TYPE 2 & $\begin{array}{l}\text { Chronic cardiorenal } \\
\text { syndrome }\end{array}$ & $\begin{array}{l}\text { It is characterized by the chronic and progressive deterioration of renal function } \\
\text { due to chronic heart failure. }\end{array}$ \\
\hline TYPE 3 & $\begin{array}{l}\text { Acute renocardiac } \\
\text { syndrome }\end{array}$ & $\begin{array}{l}\text { It consists of acute heart disorder (acute heart failure, arrhythmia or ischemia) in } \\
\text { the context of an acute kidney failure. }\end{array}$ \\
\hline TYPE 4 & $\begin{array}{l}\text { Chronic renocardiac } \\
\text { syndrome }\end{array}$ & $\begin{array}{l}\text { It is characterized by the development of a chronic heart disease (with hypertrophy } \\
\text { and left ventricular dysfunction, especially dyastolic), and an increased risk of } \\
\text { adverse cardiovascular events in the context of chronic kidney disease. }\end{array}$ \\
\hline TYPE 5 & $\begin{array}{l}\text { Secondary cardiorenal } \\
\text { syndrome }\end{array}$ & $\begin{array}{l}\text { Both organs are affected simultaneously. It usually appears as a consequence of } \\
\text { systemic diseases such as sepsis, vasculitis or amyloidosis, because the underlying } \\
\text { disease causes a simultaneous failure of both organs. }\end{array}$ \\
\hline
\end{tabular}

\section{PATHOPHYSIOLOGY}

The simultaneous failure of heart and kidney, which is characteristic of cardiorenal syndrome, is associated with several pathophysiological mechanisms.

\subsection{Low Cardiac Output}

A decrease in cardiac output such as what has been observed in heart failure causes a progressive deterioration of the glomerular filtration rate. Therefore, an inadequate renal blood flow or a decrease in the renal perfusion pressure lead to a release of tensin by the juxtaglomerular cells, with the resulting activation of the RAAS, which leads to the retention of sodium and water, the contraction of the renal afferent arterioles (thus causing a decrease in glomerular perfusion) and an increase in cardiac, vascular and renal fibrosis [2].

\subsection{Increase of Central and Intraabdominal Venous Pressure}

Cardiac output depends on the existence of a sufficiently large pressure gradient through the capillary bed. In patients with heart failure, the increase in central venous pressure reduces the pressure gradient in the glomerular capillary network, which limits the renal blood flow and leads to a deterioration of the renal function.

When there is an increase of the intra-abdominal pressure, there is an increase in the pressure of renal veins, which leads to a phenomenon similar to the increase of the central venous pressure, which in turn results in the deterioration of the renal function $[3,4]$.

\subsection{Hyperactivity of the Sympathetic Nervous System}

An increase in the systolic dysfunction of the left ventricle leads to a decrease in the renal blood flow and the renal perfusion pressure, which causes an activation of the renal sympathetic nerves and the release of catecholamines, which result in a decrease of glomerular filtration.

\subsection{Oxidative Damage and Endothelial Dysfunction}

Neurohormones trigger and mediate an oxidative damage cascade that leads to endothelial dysfunction, inflammation and cell death in cardiorenal syndrome.

\section{TREATMENT OF THE CARDIORENAL SYNDROME}

\subsection{Loop Diuretics}

The treatment of patients with type 1 or type 2 cardiorenal syndrome is extremely complicated, because the most important objectives are an improvement of cardiac function and the relief of the symptoms derived from the volume overload. This can be tried with the use of loop diuretics. However, diuretics are not always effective, because the decrease in renal perfusion prevents it from reaching its working site in the nephron, thus reducing its pharmacological action. This leads to a worsening of the heart failure and further reduces cardiac output, which means that this resistance to diuretics can lead to death. This happens when the ejection fraction drops below 35\% [2].

This is the reason why other therapies need to be implemented, such as extracorporeal ultrafiltration or peritoneal dialysis which improve the clinical state and reduce the hospitalization rate, although they cannot reduce the mortality rates for this entity [5].

\subsection{Extracorporeal Ultrafiltration}

Extracorporeal ultrafiltration, either by itself or combined with hemodialysis, is an optimal treatment to treat shortterm volume overload. This technique can improve the 
heart function by reducing the preload and eliminating neurohormonal substances. However, this technique presents the disadvantage that a fast and intermittent elimination of fluid is associated with hypotension, coronary ischemia and arrhythmias, which leads to a worsening of cardiovascular function [4]. Therefore, a more gradual elimination of the extracellular fluid is preferred, and in this case peritoneal dialysis can play a much more important role in acute cases and in long-term treatments.

\subsection{Peritoneal Dialysis}

This technique represents an optimal treatment to combat decompensate cardiac failure as a long-term therapy in patients with refractory heart failure with or without advanced chronic kidney disease; and also as a temporary support therapy until a heart transplant is performed (the only definitive treatment for type 1 and 2 cardiorenal syndrome).

Peritoneal dialysis can reduce the weight of the patient, volume overload and edema, which means that the heart function improves, and also the symptoms of hydric overload, hyponatremia and renal function, thus reducing the resistance to diuretics.

Therefore, the admission time is reduced [6,7], and so is the number of drugs used, while the quality of life significantly improves.

This technique provides considerable advantages compared with extracorporeal ultrafiltration of the dialysis, such as the fact that the fluid elimination is gradual and takes place over long periods of time, there is no need for anticoagulation and there is a possibility of an ambulatory treatment $[8,9]$.

When the technique is implemented in a situation of acute heart decompensation, low volumes must be used (750 to $1000 \mathrm{~mL}$ ), and the dialysis must be changed often (approximately every 1 - 2 hours), with dialysis solutions based on icodextrin (a glucose polymer with a high ultrafiltration potential) or hypertonic glucose, in order to prevent complications, such as the pericatheter leakage of peritoneal fluid $[10,11]$.

In long-term treatments, both intermittent peritoneal dialysis and continuous ambulatory peritoneal dialysis may be used [11]. However, this last technique offers more advantages to the patients, because it provides hemodynamic stability and the slow and gradual control of nitrogen products [12].

The dialysis scheme must be adapted to the needs of each patient and it must take into account the peritoneal transport, the residual renal function, the degree of heart deterioration, the need of control of nitrogen products, the frequency of admissions caused by heart decompensation and the response to ultrafiltration [13].

It is recommended to start with continuous ambulatory peritoneal dialysis with solutions of hypertonic glucose with short cycles and, once that the behavior of the peritoneal membrane has been assessed, this technique can be maintained or, if the patients present residual renal function or they do not need to eliminate nitrogen products, it can be replaced by automatic peritoneal dialysis with hypertonic glucose-based solutions or a night cycle of icodextrin two or three times per week [14].

In patients who do not present residual renal function and who, therefore, also need to eliminate nitrogen products, the most adequate option would be ambulatory continuous dialysis, with a night cycle of icodextrin or an automatic dialysis and the use of icodextrin in a cycle during the day [14].

The use of peritoneal dialysis in the treatment of cardiorenal syndrome is not without its complications. The amount and speed of the elimination of volume overload is less predictable than with extracorporeal ultrafiltration. Other complications are related to the insertion of a Tenckhoff catheter, pericatheter leakage, wall hematomas, surface or deep hemorrhage or peritonitis [12].

\section{CONCLUSION}

Patients who suffer from type 1 or type 2 cardiorenal syndromes present an inadequate response to high doses of diuretics, which means that other techniques are required, such as extracorporeal ultrafiltration and peritoneal dialysis. This last technique has some advantages compared with ultrafiltration, such as a higher preservation of residual renal function, a steady and slow extraction of extracellular fluid, which provides higher hemodynamic stability, a better clearance of molecules that depresses the myocardial function, a reduction of systemic inflammation, the possibility of implementing ambulatory treatment and lower costs. These advantages make this modality of dialysis the treatment of choice for cardiac failure refractory to diuretics and types 1 and 2 cardiorenal syndromes.

\section{REFERENCES}

[1] Norton, C., Georgiopoulou, V.V., Kalogeropoulos, A.P. and Butler, J. (2011) Epidemiology and cost of advanced heart failure. Progress in Cardiovascular Diseases, 54, 78-85. http://dx.doi.org/10.1016/j.pcad.2011.04.002

[2] Ellison, D.H. (2001) Diuretic therapy and resistance in congestive heart failure. Cardiology, 96, 132-143. http://dx.doi.org/10.1159/000047397

[3] Ronco, C., Haapio, M., House, A.A., Anavekar, N. and Bellomo, R. (2008) Cardiorenal syndrome. Journal of the American College of Cardiology, 52, 1527-1539. http://dx.doi.org/10.1016/j.jacc.2008.07.051

[4] Bock, J.S. and Gottlieb, S.S. (2010) Cardiorenal syndrome: New perspectives. Circulation, 121, 2592-2600. http://dx.doi.org/10.1161/CIRCULATIONAHA.109.8864 


\section{3}

[5] Nakayama, M., Nakano, H. and Nakayama, M. (2010) Novel therapeutic option for refractory heart failure in elderly patients with chronic kidney disease by incremental peritoneal dialysis. Journal of Cardiology, 55, 4954. http://dx.doi.org/10.1016/j.jjcc.2009.08.003

[6] Courivaud, C., Kazory, A., Crépin, T., Azar, R., BressonVautrin, C., et al. (2013) Peritoneal dialysis reduces the number of hospitalization days in heart failure patients refractory to diuretics. Peritoneal Dialysis International. (not yet published) http://dx.doi.org/10.3747/pdi.2012.00149

[7] Van Der Sande, F.M., Cnossen, T.T., Cornelis, T., Konings, C.J., Kooman, J.P., et al. (2012) Peritoneal dialysis in patients with heart failure. Minerva Urologica e Nefrologica, 64, 163-172.

[8] Nakayama, M. (2013) Nonuremic indication for peritoneal dialysis for refractory heart failure in cardiorenal syndrome type II: Review and perspective. Peritoneal Dialysis International, 33, 8-14. http://dx.doi.org/10.3747/pdi.2012.00014

[9] Rizkallah, J., Sood, M.M., Reslerova, M., Cordova, F., Malik, A., et al. (2013) Reduced hospitalizations in severe, refractory congestive heart failure with peritoneal dialysis: A consecutive case series. Clinical Nephrology,

\section{0, 334-341. http://dx.doi.org/10.5414/CN108038}

[10] Próchnicka, A., Krzesiński, P., Hałas, K., Dziuk, M., Niemczyk, S., et al. (2013) Diuretic-resistant congestive heart failure treated successfully with peritoneal ultrafiltration. Kardiologia Polska, 71, 393-395. http://dx.doi.org/10.5603/KP.2013.0067

[11] Kagan, A. and Rapoport, J. (2005) The role of peritoneal dialysis in the treatment of refractory heart failure. Nephrology Dialysis Transplantation, 20, vii28-vii31. http://dx.doi.org/10.1093/ndt/gfh1104

[12] Mehrotra, R. and Kathuria, P. (2006) Place of peritoneal dialysis in the management of treatment-resistant congestive heart failure. Kidney International, 70, S67-S71. http://dx.doi.org/10.1038/sj.ki.5001918

[13] Gotloib, L., Fudin, R., Yakubovich, M. and Vienken, J. (2005) Peritoneal dialysis in refractory end-stage congestive heart failure: A challenge facing a no-win situation. Nephrology Dialysis Transplantation, 20, vii32-vii36. http://dx.doi.org/10.1093/ndt/gfh1105

[14] Basile, C., Chimienti, D., Bruno, A., Cocola, S., Libutti, P., Teutonico, A., et al. (2009) Efficacy of peritoneal dialysis with icodextrin in the long-term treatment of refractory congestive heart failure. Peritoneal Dialysis International, 29, 116-118. 